\title{
Building African Ecosystem Research Network for Sustaining Local Ecosystem Goods and Services
}

\author{
Armand Sedami Igor YEVIDE ${ }^{1}$, WU Bingfang ${ }^{1}$, YU Xiubo ${ }^{2}$, LI Xiaosong ${ }^{1}$, LIU Yu ${ }^{2}$, LIU Jian ${ }^{3}$ \\ (1. Key Lab of Digital Earth Sciences, Institute of Remote Sensing and Digital Earth, Chinese Academy of Sciences, Beijing 100101, \\ China; 2. Institute of Geographical Sciences and Natural Resources Research, Chinese Academy of Sciences, Beijing 100101, China; \\ 3. International Ecosystem Management Partnership (IEMP), United Nations Environment Programme (UNEP), Beijing 100101, \\ China)
}

\begin{abstract}
A new form of producing and sharing knowledge has emerged as an international (United States of America, Asia, and Europe) research collaboration, known as the Long-Term Ecological Research (LTER) Network. Although Africa boasts rich biodiversity, including endemic species, it lacks the long-term initiatives to underpin sustainable biodiversity managements. At present, climate change may exacerbate hunger and poverty concerns in addition to resulting in ecosystem degradation, land use change, and other threats in Africa. Therefore, ecosystem monitoring was suggested to understanding the effects of climate change and setting strategies to mitigate these changes. This paper aimed to investigate ecosystem monitoring ground sites and address their coverage gaps in Africa to provide a foundation for optimizing the African Ecosystem Research Network (AERN) ground sites. The geographic coordinates and characteristics of ground sites-based ecosystem monitoring were collected from various networks aligned with the LTER implementation in Africa. Additionally, climatic data and biodiversity distribution maps were retrieved from various sources. These data were used to assess the size of existing ground sites and the gaps in description, ecosystems and biomes. The results reveal that there were 1089 sites established by various networks. Among these sites, 30.5\%, 27.5\%, and 28.8\% had no information of area, year of establishment, current status, respectively. However, $68.0 \%$ of them had an area equal to or greater than $1 \mathrm{~km}^{2}$. Sites were created progressively over the course of the years, with $68.9 \%$ being created from 2000 to 2005 . To date, only $41.5 \%$ of the sites were operational. The sites were scattered across Africa, but they were concentrated in Eastern and Southern Africa. The unbalanced distribution pattern of the sites left Central and Northern Africa hardly covered, and many unique ecosystems in Central Africa were not included. To sustain these sites, the AERN should be based on operational sites, seeking secure funding by establishing multiple partnerships.
\end{abstract}

Keywords: ecosystem monitoring; Long-Term Ecological Research (LTER); biodiversity; ground site; gap analysis; network; Africa

Citation: Yevide Armand Sedami Igor, Wu Bingfang, Yu Xiubo, Li Xiaosong, Liu Yu, Liu Jian, 2015. Building African Ecosystem Research Network for sustaining local ecosystem goods and services. Chinese Geographical Science, 25(4): 414-425. doi: 10.1007/s 11769-015-0767-9

\section{Introduction}

The most important aspect of nature to human beings is the diversity of life forms and landscapes it creates, i.e., biodiversity (Liu et al., 2011). In 1986, Walter G. Rosen introduced the term of biodiversity and the United Nations Convention on Biological Diversity signed in 1992 further promoted this idea (Wilson, 1988; Blackmore, 2002). Biodiversity is assessed at various levels from genes to ecosystems (Liu et al., 2011; Stork and Astrin, 2014). Biodiversity is vital for human beings, as it provides important goods and services, such as food, wood for energy and construction, plants for pharmaceutical production, and many recreational areas (Roda, 2002;

Received date: 2014-08-26; accepted date: 2014-12-29

Foundation item: Under the auspices of National Natural Science Foundation of China (No. 31161140355)

Corresponding author: WU Bingfang. E-mail: wubf@radi.ac.cn

(C) Science Press, Northeast Institute of Geography and Agroecology, CAS and Springer-Verlag Berlin Heidelberg 2015 
Girard et al., 2003; Sales, 2003; Belem et al., 2008; Da Silva et al., 2008; Leciak and Bah, 2008; Ren et al., 2009).

However, human activities often lead to a loss in biodiversity. Indeed, the rapid human population growth, urbanization, industrialization, agriculture and tourism development are creating and increasing changes in ecosystems and introducing hazards to species where they previously did not encountered threats (Boahene, 1998; Casse et al., 2004; Asongu, 2013). Medicinal and aromatic plant harvesting, tree logging, extensive overgrazing, mining, illegal and over-hunting dwindled ecosystems' coverage, leading to habitat losses and the extinction or near extinction of many species. Climate change exacerbates biodiversity loss through drought, flooding and other climate-related disasters (Sala et al., 2000; Rarieya and Fortun, 2010; Estes et al., 2013; Heubes et al., 2013). In addition, alien invasive species contribute to biodiversity loss and remain a topical issue in biodiversity conservation (Berglund et al., 2013; Rejmanek and Richardson, 2013; Luque et al., 2014; Padmanaba and Corlett, 2014; Roy et al., 2014).

Apart from climate hazards that can wipe out incredibly biological diversity in a short time, most of the other threats leading to biodiversity loss emerge rather slowly over decades or centuries, making it impossible to sense the symptoms with any precision (Kim, 2006). On the other hand, the unpredictability of the temporal and spatial scales of most climate-related disasters makes it difficult to obtain real time data on the phenomenon to study its manifestation, consequences and the response of biotic and abiotic factors. Therefore, extensive research and careful analyses of relevant data over a longer period of time are required for a better understanding and the sustainable management of the biotic and abiotic components of ecosystems (Kim, 2006). A new form of producing and sharing knowledge has emerged as an international research collaboration known as the Long-Term Ecological Research (LTER) Network (Vihervaara et al., 2013).

The LTER started in the United States of America in 1980 through establishment of the US Long-Term Ecological Research Network (US LTER Network). The US LTER Network was founded by the US National Science Foundation (NSF) to support a large and diverse portfolio of long-term ecological experiments (Knapp et al., 2012). This network consists of 26 sites scattered in forest, grassland, desert, freshwater, coastal and other ecosystems that span a broad geographic range including both climate and human impacts (Robertson et al., 2012). By increasingly being engaged with diverse stakeholders (i.e., land managers, policymakers, and decision-makers) at all levels, it provides not only scientists with key places for long-term, biome-specific observations and experimentation, but also ensures that their inquiries are relevant to addressing societal concerns (Driscoll et al., 2012). The sites are closely associated with educational institutions and serve undergraduates, graduates and postgraduates to conduct field research, as well as provide environmental training for community leaders. Although the US LTER Network was not designed to be a single integrated observatory in which each site employs standardized instrumentation and capacity, cross-sites observation and analysis has considerably evolved since 1992 (Robertson et al., 2012). To date, more than 17000 peer-reviewed publications have been generated from the long-term studies documenting patterns of inorganic inputs and nutrient movement through soils, surface waters, and groundwater; patterns and control of primary productivity and organic matter accumulation; spatial and temporal distributions of populations representing trophic structures; and ecological responses to varying patterns and the frequency of site disturbance (Michener and Waide, 2009).

The Chinese Ecosystem Research Network (CERN), supported by the Chinese Academy of Sciences, was the second LTER Network established. Launched in 1988, CERN is composed of one synthesis center, 5 sub-centers and 46 field stations covering cropland, forest, grassland, desert, marshes, lakes, bays and urban ecosystems. CERN aims to obtain scientific data of ecosystem change through monitoring, research and demonstrations to provide techniques and scientific suggestions to decision-makers for national ecosystem management, agricultural production and ecological remediation ( $\mathrm{Fu}$ et al., 2010). While each site has its own scientific problems and specific regional characters, all of the sites are required to perform four common research areas to ensure cross-site and network-level comparisons: biotic communities composition and structure; ecosystem productivity, energy flow and materials cycles; interactions between humans, environment and ecosystem; and ecosystem management 
and acclimation to global changes. With over 2000 scientists, technicians and graduate students engaged in its activities, CERN is one of the largest national networks worldwide and an important member of the International Long-Term Ecological Research (ILTER) Network created in 1993. The ILTER is a 'network of networks', in terms of a global network of research sites (Kim, 2006; Fu et al., 2010; Vihervaara et al., 2013).

Regarding LTER, Africa is ranked behind other continents that own national to regional and even continental scale monitoring networks (Gray and Kalpers, 2005; Saidi and Pauw, 2010; Jürgens et al., 2012). However, Africa has many programs and projects involving wildlife conservation and ecosystem monitoring through International Non-Governmental Organizations (INGOs) initiatives. These INGOs address biodiversity issues, especially wildlife conservation, and work in partnership with countries through local contacts, such as Non-Governmental Organizations (NGOs), associations and governmental authorities which are site owners. Apart from the INGOs, there are initiatives at both national and regional scales dedicated to the long-term monitoring of biodiversity in Africa. Some examples of these initiatives are: the Gobabeb Research and Training Centre (GOBABEB); BirdLife International; Sahara and Sahel Observatory (ROSELT/OSS); Biodiversity Monitoring Transect Analysis in Africa (BIOTA-AFRICA); South African Environmental Observation Network (SAEON); Tropical Ecology Assessment and Monitoring Network (TEAM); and the Global Observation Research Initiatives in Alpine environment (GLORIA) (ROSELT/OSS, 2004; Bennun et al., 2005; Gray and Kalpers, 2005; Joubert and Trollip, 2011; Jürgens et al., 2012; Henschel and Lancaster, 2013).

The African Ministerial Conference on the Environment (AMCEN) was aware of the challenges of climate change and the importance of monitoring in ecosystem management. In 2010, it requested the establishment of an 'African Ecosystem Research Network' (AERN) as the long-term ecological infrastructure to support sustainable management through sound decisions, for the well-being of the African population. The National Natural Science Foundation of China (NSFC) is funding a collaborative project with the United Nations Environment Programme (UNEP) and facilitated by the International Ecosystem Management Partnership (IEMP) to help build ecological resilience for sustainable development in Africa. In this context, this paper is aimed to investigate ecosystem monitoring ground sites and address their coverage gaps in Africa to provide a foundation in optimizing the AERN ground sites.

\section{Materials and Methods}

\subsection{Study area}

Africa is the world's second-largest continent and covers approximately $3.02 \times 10^{7} \mathrm{~km}^{2}$, which represents $6 \%$ of the earth's total area and $20.4 \%$ of the total land area. Africa is subdivided into five regions (northern, western, central or middle, eastern and southern), according to the United Nations geographic classification scheme (Fig. 1). Regarding this subdivision, the eastern and western Africa are almost even in terms of the number of countries, and together they have more than $61 \%$ of Africa's countries. However, the northern region is the widest and covers $27 \%$ of Africa's total area, followed by the central region $(22 \%)$. The southern region is the smallest $(10 \%$ of area) and has the fewest number of countries $(10 \%)$.

The Koeppen climate classification identifies three main types of climate that characterize Africa: tropical, temperate and dry. The tropical climate stretches over areas located in the western, central and eastern regions, while the temperate climate influence is found in every region, except the western. The largest part of Africa is under a dry climate, and this makes Africa the hottest continent on earth (Fig. 1). The mean annual temperature ranges from $-5.0^{\circ} \mathrm{C}$ to $32.0^{\circ} \mathrm{C}$, with a maximum temperature of $49.0^{\circ} \mathrm{C}$ during the warmest months. There are areas that receive no precipitation during the year and others that may have precipitation every week.

The new harmonized soil map at the continental scale for Africa had 29 dominant soil units and showed that over $60 \%$ of the soil types represent hot, arid or immature soil assemblages including Arenosols, Leptosols, Cambisols, Calcisols, Regosols and Solonchacks/Solonetz (Dewitte et al., 2013). Due to the climate and soil patterns, Africa has approximately 114 ecosystems gathered into 9 biomes. The tropical and subtropical grasslands, savannas, and shrublands as well as the deserts and xeric shrublands are the dominant vegetation types covering $79 \%$ of Africa (Olson et al., 2001). The continent has enormous wetlands of international significance, including Lake Victoria, the world's second largest lake. Its mainland harbors between 40000 and 


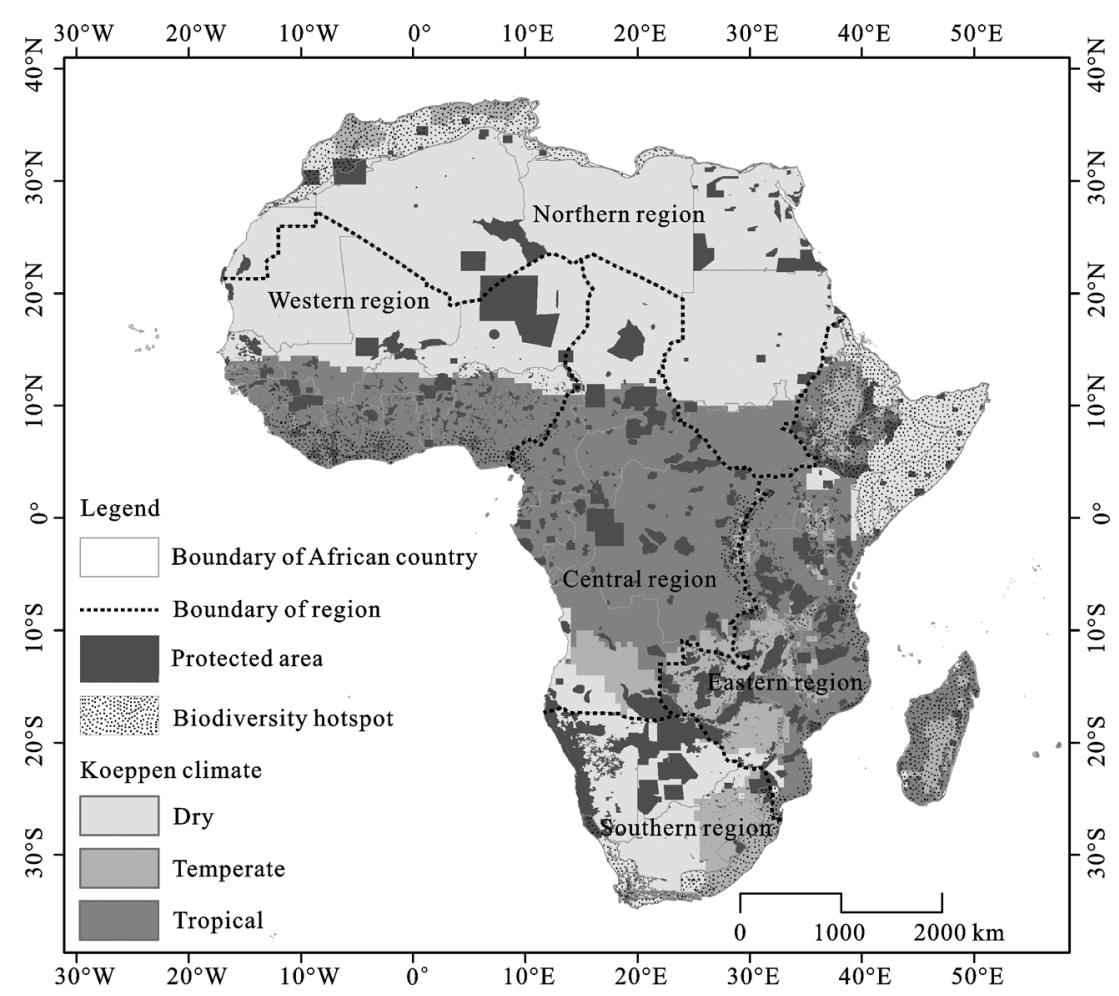

Fig. 1 Geographic location of Africa and distribution of protected areas, biodiversity hotspots and Koeppen climates

60000 plant species, one quarter of the world's 4700 mammal species, more than 2000 species of birds, approximately 100000 known species of insects and arachnids, and at least 2000 species of fish alongside 950 amphibian species (UNEP, 2010). Eight of the world's 34 biodiversity hotspots are in Africa, making the continent home to an enormous amount of endemic species (Conservation International, 2011).

Although Africa brims with natural resources, it remains the poorest and most underdeveloped continent. Its population has increased rapidly since 1950 , growing from $2.21 \times 10^{8}$ to $1.10 \times 10^{9}$ by 2013 . There are a greater percentage of females than males, and the population remains very young, with more than half of the inhabitants less than 25 years of age. The population density is null in some parts of the continent, especially in the desert where water scarcity makes living impossible. The western and eastern regions are more populated than other regions and account for nearly $50 \%$ of the area, wherein the population density is above 10 persons $/ \mathrm{km}^{2}$.

\subsection{Data collection and processing}

The geographic coordinates of site-based monitoring, climatic and biodiversity data were collected from vari- ous sources and used in this study.

The geographic coordinates of the ground sites were collected from networks that provided free access to the location of their sites. The focus was on the following networks: BirdLife International; the Global Environment Monitoring System (GEMS); the Mountain Research Initiative (MRI); the Tropical Ecology Assessment and Monitoring Network (TEAM); the Global Observation Research Initiative in Alpine Environments (GLORIA); the Sahara and Sahel Observatory (ROSELT/OSS); the Biodiversity Monitoring Transect Analysis in Africa (BIOTA-AFRICA); the South African Environmental Observation Network (SAEON); the Gobabeb Research and Training Centre (GOBABEB); and the Malawi Long-Term Ecological Research (Malawi-LTER). For BirdLife International, only the Important Bird and Biodiversity Areas (IBAs) belonging to its African partner countries were considered, and sites located in islands were removed, except those in Madagascar. In addition, a few other active ground sites established in Africa by China and some African research centers were considered. For each network and/or site, characteristics such as size, establishment date, targeted ecosystems, type of funding, and current implementation status were collected when available. 
Climatic data, including mean annual precipitation and temperature of high resolution (30 arc-seconds), were collected from WorldClim (http://www.worldclim.org), which provides scientists with free access to current climatic conditions based on data over fifty years (1950 to 2000). The precipitation and temperature values were extracted from collected raster files for each ground site and were used to determine the number of dry months, which represents the number of months characterized by negative values of precipitation in millimeter minus two times the temperature in degree Celsius.

Biodiversity data were retrieved from the World Database on Protected Areas (WDPA), the Conservation International Foundation (CI), and the World Wildlife Fund (WWF). Data consisted of the protected areas distribution map (UNEP-WCMC, 2012), biodiversity hotspots distribution (Conservation International, 2011) and the distribution of biomes in Africa (Olson et al., 2001). The location of sites in biodiversity hotspots and/or in only protected areas was also noted for all of the considered ground sites. The assessment of the biomes and eco-regions coverage gap was based on the comparison of the numbers and the extent of the eco-regions in Africa and those sites that are covered. The identification of biomes and eco-regions observatory sites covered was done by projecting in the same view both layers of eco-regions distribution and sites waypoints, and establishing a buffer zone of $1 \mathrm{~km}$ radius $\left(3.14 \mathrm{~km}^{2}\right)$ around sites. We chose the $1 \mathrm{~km}$ radius buffer because the circle area largely included the wide range of phytosociologic inventory plots and the standardized $1 \mathrm{~km}^{2}$ plots often used for monitoring. Data treatment and mapping were made under ArcMap version 10.1.

\section{Results}

\subsection{Network and site distribution across Africa}

According to the literature and information retrieved from the considered networks, initiatives similar to the LTER started in Africa in 1962 by the establishment of the Namib Desert Research Station (NDRS), which underwent several name changes to its current name, the Gobabeb Research Training Center, in 1998 (Henschel and Lancaster, 2013). After the Convention on Biological Diversity was signed in 1992, there was an increase in LTER Networks establishment in Africa. Sites were progressively installed across the continent by: ROSELT/
OSS in 1992 (Aïdoud et al., 2008); BIOTA-AFRICA in 2000 (Jürgens et al., 2012); SAEON in 2002 (Joubert and Trollip, 2011); TEAM in 2008 (www.teamnetwork. org); GLORIA in 2011 (www.gloria.ac.at); and MRI in 2012 (http://mri.scnatweb.ch).

Approximately 10 networks were aligned with the long-term ecosystem monitoring initiatives and together they have established approximately 1640 sites. Of these sites, only 1089 (66.4\%) fulfilled the stated conditions and were considered for further analysis. They spread across areas characterized by 0 or 12 dry months (humid or dry climate) to 1 to 12 dry months (multiple seasons) (Table 1). Most sites (94.1\%) belong to the BirdLife International, the Global Environment Monitoring Systems (GEMS) and the BIOTA-AFRICA. They targeted the entire continent for the implementation of their activities, while the others were established for estate sovereignty focusing on ecosystems in a single country such as: South Africa for SAEON; Namibia for GOBABEB; and Malawi for Malawi-LTER. Others were established for specific ecosystems, such as tropical forests for TEAM and mountain ecosystems for MRI and GLORIA. As a result, some networks were absent from some African regions. The eastern, southern and central regions hosted 9, 7 and 3 networks, respectively. Approximately $64 \%$ of the sites were embedded in eastern and southern Africa, leaving the other regions and especially the central region scarcely covered (Table 1).

\subsection{Ground site characteristics and biome cover- age assessment}

Approximately $24.3 \%$ of the sites were established outside hotspots and protected areas boundaries, while $26.2 \%$ were located in both hotspots and protected areas (Table 2). Many sites lack comprehensive information regarding size, setting date, and current implementation status. BirdLife International, BIOTA-AFRICA and TEAM provides comprehensive descriptions for many of their sites, while Malawi-LTER seems to exist in name only and had no details on its site. Of the sites, $30.5 \%, 27.5 \%$ and $28.8 \%$ have no information on their area, year of establishment, and current functioning status, respectively (Table 2 and Table 3). However, $68.0 \%$ had an area greater or equal to $1 \mathrm{~km}^{2}$. Sites were created progressively over the years, but the majority were created from 2000 to 2005 (68.9\%). To date, only $41.5 \%$ were functional. 
Table 1 Distribution of networks and their ground sites in African regions and site distribution in classes of dry months

\begin{tabular}{|c|c|c|c|c|c|c|c|c|c|c|c|c|c|}
\hline \multirow{2}{*}{ Network } & \multicolumn{5}{|c|}{ African region } & \multicolumn{7}{|c|}{ Number of dry month } & \multirow{2}{*}{ Tota } \\
\hline & Central & Eastern & Northern & Southern & Western & No data & 0 & $<3$ & $3-5$ & $6-8$ & $9-11$ & 12 & \\
\hline BIOTA-AFRICA & & 3 & 12 & 37 & 14 & & 2 & 3 & 9 & 20 & 15 & 17 & 66 \\
\hline BirdLife & 33 & 338 & 100 & 107 & 109 & 13 & 68 & 112 & 219 & 193 & 37 & 45 & 687 \\
\hline GEMS & 2 & 48 & 79 & 108 & 35 & 1 & 8 & 15 & 134 & 74 & 24 & 16 & 272 \\
\hline GLORIA & & 2 & 1 & & & & 2 & 1 & & & & & 3 \\
\hline GOBABEB & & & & 1 & & & & & & & & 1 & 1 \\
\hline Malawi-LTER & & 1 & & & & & & 1 & & & & & 1 \\
\hline MRI & & 11 & & 6 & & & 6 & 4 & 6 & 1 & & & 17 \\
\hline Other & & 10 & & 1 & 1 & & 2 & 1 & 5 & 3 & & 1 & 12 \\
\hline ROSETL/OSS & & 2 & 4 & & 6 & & & & & 4 & 6 & 2 & 12 \\
\hline SAEON & & & & 10 & & 1 & & 1 & 3 & 4 & & 1 & 10 \\
\hline TEAM & 2 & 6 & & & & & 3 & 3 & 2 & & & & 8 \\
\hline Total & 37 & 421 & 196 & 270 & 165 & 15 & 91 & 141 & 378 & 299 & 82 & 83 & 1089 \\
\hline
\end{tabular}

Notes: BIOTA-AFRICA is Biodiversity Monitoring Transect Analysis in Africa; BirdLife is BirdLife International; GEMS means Global Environment Monitoring System; GLORIA is Global Observation Research Initiative in Alpine Environments; GOBABEB represents Gobabeb Research and Training Centre; Malawi-LTER means Malawi Long-Term Ecological Research; MRI is Mountain Research Initiative; ROSETL/OSS represents Sahara and Sahel Observatory; SAEON is South African Environmental Observation Network; TEAM means Tropical Ecology Assessment and Monitoring Network

Table 2 Distribution of sites in according to their area and location in hotspots or coldspots of biodiversity

\begin{tabular}{|c|c|c|c|c|c|c|c|c|c|c|}
\hline \multirow{2}{*}{ Network } & \multicolumn{6}{|c|}{ Area $\left(\mathrm{km}^{2}\right)$} & \multicolumn{4}{|c|}{ Biodiversity hotspots and coldspots } \\
\hline & $<1$ & $1-10$ & $10-100$ & $100-1000$ & $\geq 1000$ & Unknown & HS \& PA & HS & PA & None \\
\hline BIOTA-AFRICA & & 66 & & & & & 15 & 9 & 20 & 22 \\
\hline BirdLife & 16 & 67 & 148 & 292 & 164 & & 207 & 194 & 143 & 143 \\
\hline GEMS & & & & & & 272 & 48 & 120 & 27 & 77 \\
\hline GLORIA & & & & & & 3 & 3 & & & \\
\hline GOBABEB & & & & & & 1 & & & 1 & \\
\hline Malawi-LTER & & & & & & 1 & & & & 1 \\
\hline MRI & & & & & & 17 & 2 & 4 & & 11 \\
\hline Other & & & & & & 12 & 2 & 4 & 2 & 4 \\
\hline ROSETL/OSS & & & & & & 12 & 1 & 2 & 5 & 4 \\
\hline SAEON & & & & & & 10 & 3 & 3 & 3 & 1 \\
\hline TEAM & & & & 1 & 3 & 4 & 4 & 1 & 1 & 2 \\
\hline Total & 16 & 133 & 148 & 293 & 167 & 332 & 285 & 337 & 202 & 265 \\
\hline
\end{tabular}

Notes: HS \& PA mean sites located in both hotspots and protected areas. HS means sites located in only hotspots. PA means sites located in only protected areas. None represents sites located outside both protected areas and hotspots. Meanings of other abbreviations see Table 1

Table 3 Site distribution according to date of establishment and current functioning status

\begin{tabular}{|c|c|c|c|c|c|c|c|}
\hline \multirow{2}{*}{ Network } & \multicolumn{4}{|c|}{ Site establishment date } & \multicolumn{3}{|c|}{ Site current functioning status } \\
\hline & Before 2000 & $2000-2004$ & From 2005 & Unknown & Closed & Functional & Unknown \\
\hline BIOTA-AFRICA & & 35 & 11 & 20 & 66 & & \\
\hline BirdLife & & 687 & & & & 427 & 260 \\
\hline GEMS & & 24 & 16 & 232 & 257 & & 15 \\
\hline GLORIA & & & 3 & & & 3 & \\
\hline GOBABEB & & & & 1 & & 1 & \\
\hline Malawi-LTER & & & & 1 & & & 1 \\
\hline MRI & & & & 17 & & & 17 \\
\hline Other & & & & 12 & & 4 & 8 \\
\hline ROSETL/OSS & 2 & 4 & & 6 & & & 12 \\
\hline SAEON & & & & 10 & & 10 & \\
\hline TEAM & & & 7 & 1 & & 7 & 1 \\
\hline Total & 2 & 750 & 37 & 300 & 323 & 452 & 314 \\
\hline
\end{tabular}

Note: Meanings of all abbreviations see Table 1 
Regardless of the information gap, the considered sites covered the 9 biomes which characterize Africa's landscape. However, although $30 \%$ of the sites were contained in the tropical and subtropical grasslands, savannas, and shrublands, the Mediterranean forests, woodlands, and scrub, as well as the Montane grasslands and shrublands, hosted $32 \%$ of the sites even though they were not the widest biomes (Fig. 2). Additionally, the pattern of sites within the biomes showed an aggregate distribution (i.e., sites were greatly concentrated in some areas of biomes across regions). The evidence of pattern was observed in the distribution of sites in Africa's widest biomes. There were fewer sites within the tropical and subtropical grasslands, savannas, and shrublands in the central and northern Africa than in the other regions. There were also fewer sites in the deserts and xeric shrublands in the northern and western regions. The biome coverage gap appeared to be in the central Africa, especially within the tropical and subtropical moist broadleaf forests (Fig. 3a). When limited to only functional sites, the coverage gap in the deserts and xeric shrublands biome widened (Fig. 3b).

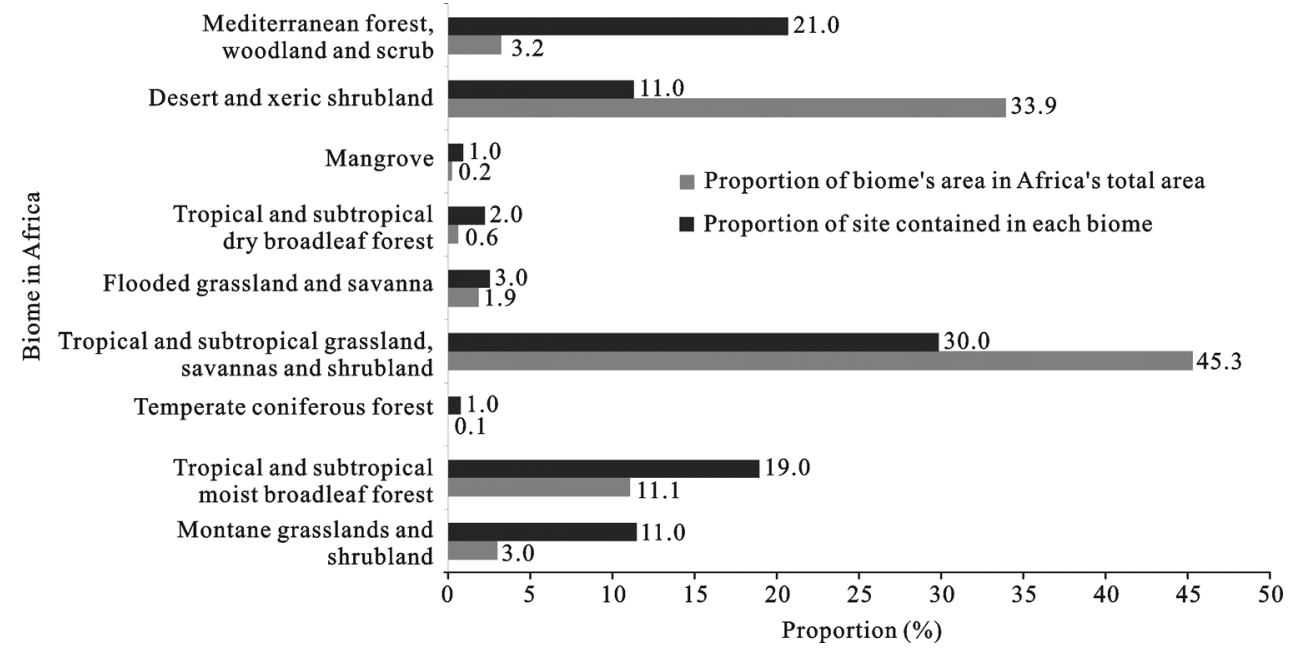

Fig. 2 Proportion of biome's areas and proportion of contained sites
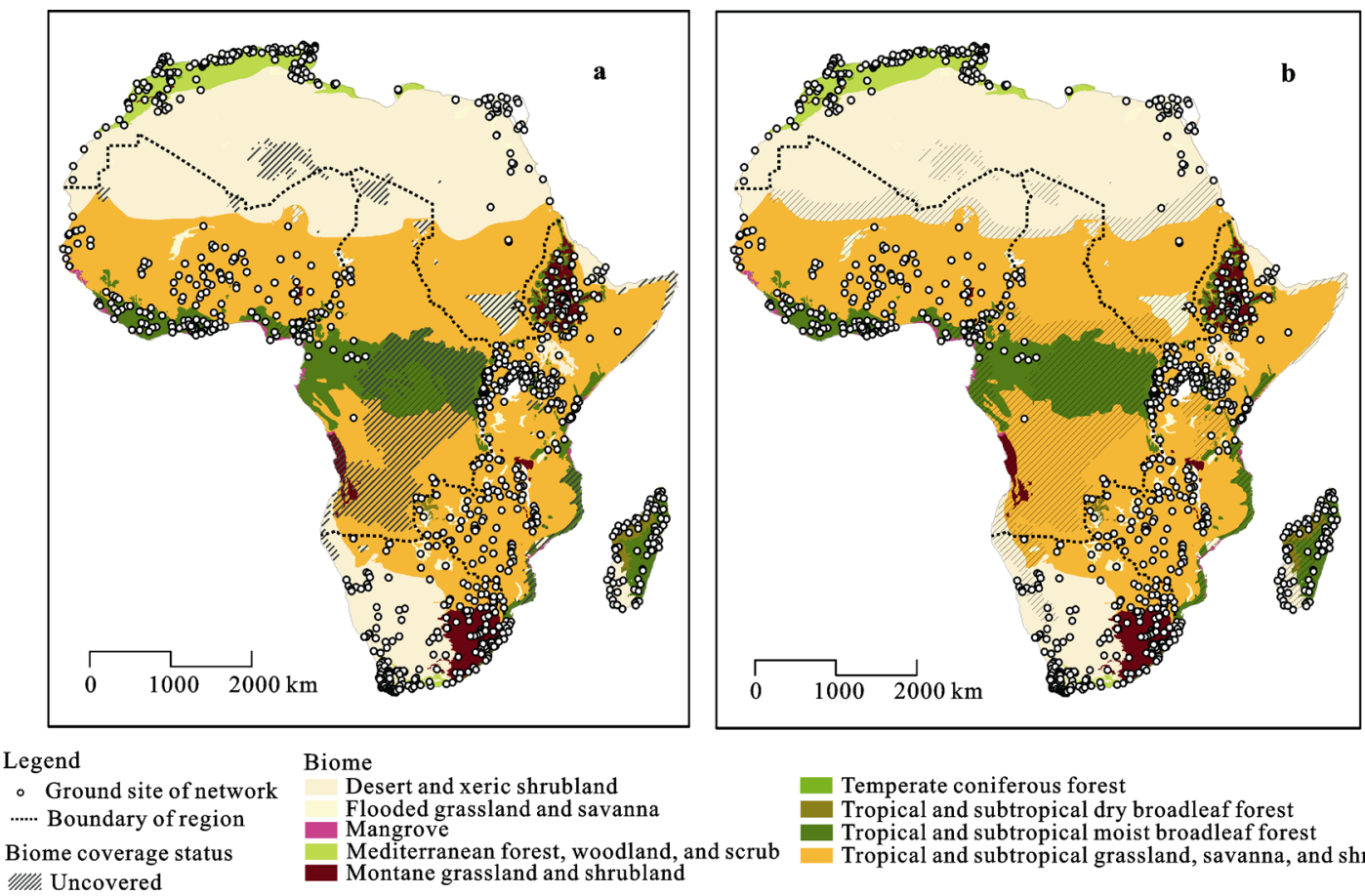

Temperate coniferous forest

Tropical and subtropical dry broadleaf forest

Tropical and subtropical moist broadleaf forest

Tropical and subtropical grassland, savanna, and shrubland yIIIf, Uncovered

Fig. 3 Distribution of ground sites in biomes and coverage gap status for all considered sites (a) and for functional sites only (b) 


\section{Discussion}

\subsection{Long-Term Ecological Research (LTER) in Africa}

Climate change and anthropogenic factors affect the entire globe, and Africa could suffer the most from global warming. The need for African ecosystems resilience boosting and disaster watch is obvious to enable the population welfare, with evident feedback on the mitigation of climate change. A LTER Network for ecosystems monitoring at local, regional and continental scales are relevant to shed light on the drivers of change and how they can be influenced to increase ecosystem resilience (Yin and Yin, 2010; Chen et al., 2012). Such an initiative exists in the US, Asia, and Europe since the 1980s (Lane, 1997; Fu et al., 2010; Knapp et al., 2012). Although the oldest network Gobabeb Research and Training Centre (GOBABEB) was established in Africa in 1962 and boasts more than 50-year research on the Namib (Henschel and Lancaster, 2013), interest in environmental research in the southern Africa emerged in the 1980s. It led to the mushrooming of regional environmental research networks since the 1990s, but many of the established networks never became active (Saidi and Pauw, 2010). The Environmental Long-Term Observatories Network of the Southern Africa (ELTOSA) was established in 2001 by networks from Malawi, Mozambique, Namibia, South Africa and Zambia (Henschel et al., 2003). ELTOSA aimed to coordinate the regional planning of environmental observatories' networks; facilitate regional research collaboration; standardize research and data handling protocols; and ensure data sharing and dissemination. However, it has been inactive and unproductive for much of its existence (Saidi and Pauw, 2010). ELTOSA implementation has been constrained by funding, and most country scale networks exist only in name and lack visibility and information on their site (see the case of Malawi-LTER in Table 2 and Table 3). Only SAEON, which has guaranteed funding from South African government through the National Research Foundation (NRF), has effectively sustained a long-term implementation (Saidi and Pauw, 2010; Joubert and Trollip, 2011).

BIOTA-AFRICA was launched in 2000 and is supported by the German Federal Ministry of Education and Research (BMBF). It is the first project to initiate a long-term biodiversity monitoring network across Africa
(Jürgens et al., 2012). Its goal was to create scientific support for decision makers for conservation planning and for a feasible and sustainable management of the use of biodiversity. Based on project funds, its activities were implemented in three phases until 2010. For most of its sites, two phases were implemented, and the longest vascular plant data collection was completed in the northern and southern Africa (Jürgens et al., 2012).

Sustainable funding is needed for LTER implementation that extends over several decades. It could not be based solely on project funds, as LTER is known to be expensive (Tenhinds, 1984; Bennun et al., 2005; Saidi and Pauw, 2010; Joubert and Trollip, 2011). The US LTER and the CERN lasted more than three decades because they were supported by periodic renewed governmental funding ( $\mathrm{Fu}$ et al., 2010; Robertson et al., 2012). The United Kingdom Environmental Change Network (ECN) was established in 1992. It has 14 sponsors to finance long-term monitoring implementation across its 12 terrestrial and 45 freshwater sites (Lane, 1997).

The establishment of AERN should be planned to overcome funding disruption through secure fund sources by gathering institutions that are willing to contribute to LTER in Africa. However, these institutions should also consist of African institutions, to ensure that scientists' inquiries are relevant to addressing societal concerns at local, regional, and continental scales (Saidi and Pauw, 2010; Driscoll et al., 2012).

\subsection{Ground sites distribution and gaps in ecosys- tem and biome coverage}

Africa has a huge number of ground site-based ecosystem monitoring heritage. The study considered 1089 sites spread across various types of climates ranging from hyper arid to equatorial. Of these sites, $68.0 \%$ have more than $1 \mathrm{~km}^{2}$ and $68.9 \%$ were established from 2000 to 2005 . Indeed, this time period corresponds to the establishment of BIOTA-AFRICA (Jürgens et al., 2012); the assessment of IBAs (BirdLife International, 2002; Bennun et al., 2005); and the SAEON launch (Joubert and Trollip, 2011). This shows the very little experience of Africa in LTER and justifies the weaknesses and persistent gaps which characterize Africa's climate information system (Archer et al., 2007), as LTER always includes investigations on biotic and abiotic factors (Lane, 1997; Hobbie et al., 2003; Jürgens et al., 2012; 
Robertson et al., 2012; Vihervaara et al., 2013). Biodiversity conservation is the main concern of any LTER, and $75.7 \%$ of the sites were located in biodiversity hotspots or protected areas. The IBAs were identified to ensure the long-term viability of naturally occurring bird populations (BirdLife International, 2002; Bennun et al., 2005). Therefore, they represent the areas of conservation interest because birds are effective biodiversity indicators, as they require various biotas for their lifecycle (Machange et al., 2005; Newman et al., 2007; Hartz et al., 2012; Ogden et al., 2014a; 2014b). Although 24.3\% of the sites were outside both hotspots and protected areas boundaries, more than half belonged to BirdLife International. It based its IBAs network to shorten gaps in protected areas systems which were insufficient to preserve the Earth's biodiversity (Wiens et al., 2009). Therefore, such a site is relevant to shed light on diversity and the dynamic of species and habitats currently unconsidered in biodiversity hotspots and protected areas distribution.

Overall, Africa's biomes were covered by sites, even though 24 and 49 ecosystems were devoid of sites for all of the considered sites or the current functional sites, respectively. These ecosystems included many unique ecosystems located in the central and northern Africa, such as the Angolan Miombo woodlands; the northeastern and central Congolian lowland forests; the northern and southern Congolian forest-savanna mosaic; and South Saharan steppe and woodlands. These uncovered ecosystems were embedded in Angola and the Democratic Republic of Congo, which have been plagued by civil wars for decades. The unsecure political status remains the main reason for this gap in their ecosystems coverage. Remote sensors could be a useful alternative to collect and provide data on uncovered ecosystems in less safe African countries, because sensors can collect and transfer data without much manpower. However, great care should be paid to the calibration and data control for good data quality (Taylor and Loescher, 2013).

In spite of regional, ecosystem and biome gaps expressed by ground sites distribution across Africa, there were approximately 400 sites currently functional with areas equal to or greater than $1 \mathrm{~km}^{2}$, which encompassed hyper arid to equatorial climates (Fig. 4). This number is 9 times more than the number of sites that belong to the Chinese Ecosystem Research Network (CERN), and 15

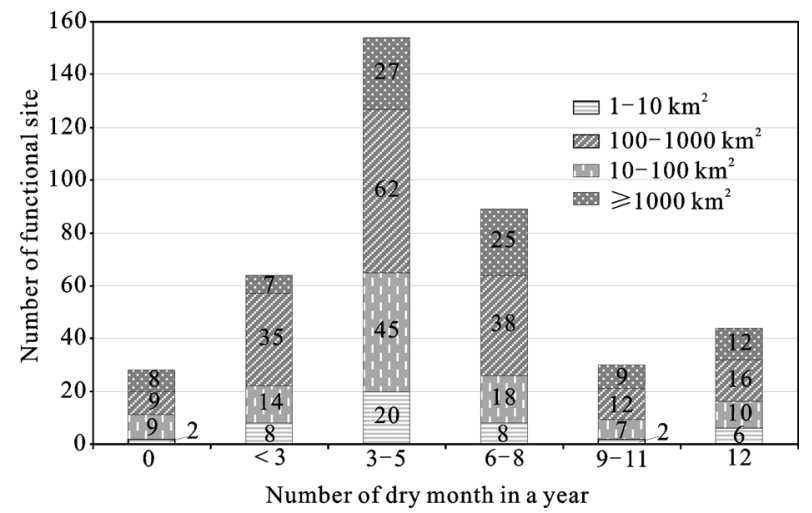

Fig. 4 Distribution of functional sites having an area equal to or greater than $1 \mathrm{~km}^{2}$ across number of dry months in a year

times more than that belong to the US Long-Term Ecological Research Network (Fu et al., 2010; Knapp et al., 2012; Robertson et al., 2012). They were concentrated in the southern region (Botswana and South Africa); the eastern region (Ethiopia, Uganda and Zimbabwe); the western region (Burkina-Faso, Ghana and Nigeria); and the northern region (Egypt, Morocco and Tunisia) (Fig. 5). These countries could be targeted first to build the AERN, and then expand the network to the central region and other countries.

\section{Conclusions}

Ecosystem monitoring is arguably the most important tool for discovering unexpected ecological trends and detecting the early warning signs of environmental harm. This monitoring is essential for Africa, which is struggling to overcome many challenges, including food security and climate change, to set up a continental scale ecosystem monitoring platform for sound ecosystem management decision making. In fact, this could provide decision makers with the necessary guidance for both ecosystem and people resilience.

Africa has a huge legacy of ground site-based ecosystem monitoring. However, many sites lack a comprehensive description, and some LTER networks exist in name only. In addition, there is an unbalanced distribution pattern of sites which has left central and northern Africa barely covered; and many unique ecosystems in the central Africa are not included.

To sustain the AERN, it should base its establishment on functional sites located in the southern, eastern, northern and western Africa and then expand its network of sites to the central region and other countries. The 


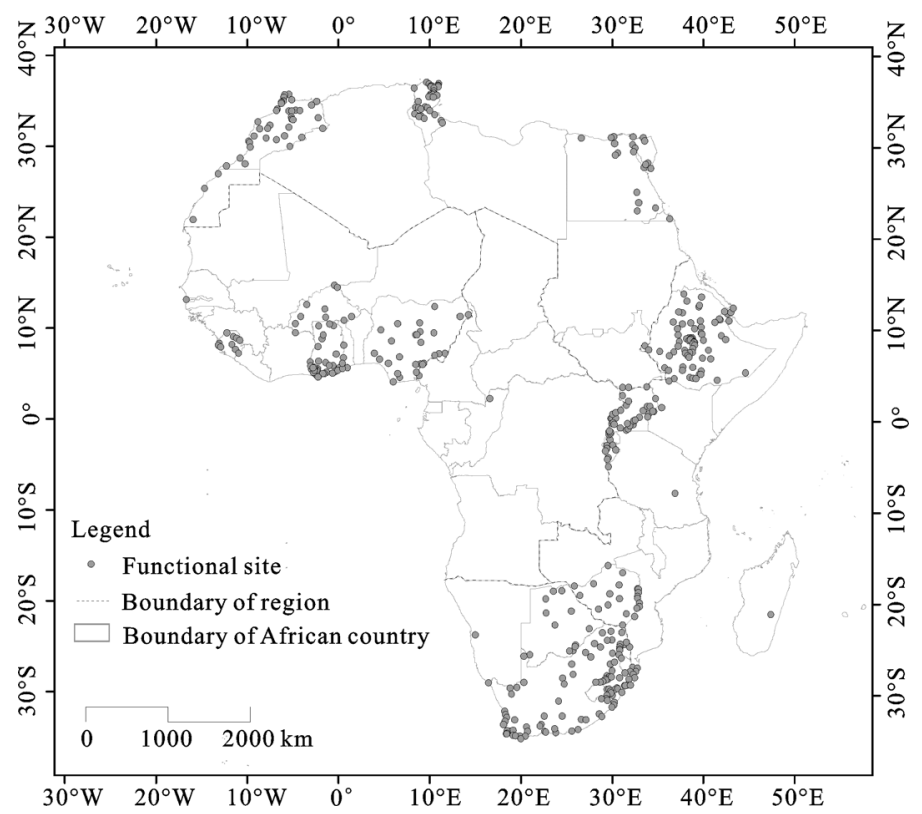

Fig. 5 Distribution of functional sites across countries in Africa

AERN should seek secure funding through multiple partnership establishments, including many with African institutions to ensure that scientists' inquiries are relevant to addressing societal concerns at local, regional, and continental scales.

\section{Acknowledgements}

We express our gratitude to the Chinese Academy of Sciences which gave us necessary facilities to undertake this study. The first author is grateful to Ahmed Khan and René Gommes for providing editorial inputs and also grateful to Miss Zheng Zhaoju for technical assistance.

\section{References}

Aïdoud A, Jauffret S, Sakona Y, 2008. Long-term Environmental Monitoring in a Circum-Saharan Network: the ROSELT/OSS Experience. OSS Synthesis Collection 3. Tunis: OSS, Tunis.

Archer E, Mukhala E, Walker S et al., 2007. Sustaining agricultural production and food security in Southern Africa: an improved role for climate prediction? Climatic Change, 83(3): 287-300. doi: 10.1007/s10584-006-9192-5

Asongu S A, 2013. How would population growth affect investment in the future? Asymmetric panel causality evidence for Africa. African Development Review, 25(1): 14-29.

Belem B, Olsen S C, Theilade I et al., 2008. Identification des arbres hors forêt préférés des populations du Sanmatenga (Burkina Faso). Bois et Forêts des Tropiques, 298(4): 53-64. (in French)
Bennun L, Matiku P, Mulwa R et al., 2005. Monitoring important bird areas in Africa: towards sustainable and scaleable system. Biodiversity and Conservation, 14(11): 2575-2590.

Berglund H, Jaremo J, Bengtsson G, 2013. Associations of invasive alien species and other threats to IUCN Red List species (Chordata: vertebrates). Biological Invasions, 15(5): 11691180. doi: 10.1007/s10530-012-0359-x

BirdLife International, 2002. Important Bird Areas and Potential Ramsar Sites in Africa. Cambridge, UK: BirdLife International. Blackmore S, 2002. Biodiversity update-progress in taxonomy. Science, 298(5592): 365-365. doi: 10.1126/science.1075026

Boahene K, 1998. The challenge of deforestation in tropical Africa: reflections on its principal causes, consequences and solutions. Land Degradation \& Development, 9(3): 247-258.

Casse T, Milhoj A, Ranaivoson S et al., 2004. Causes of deforestation in southwestern Madagascar: what do we know? Forest Policy and Economics, 6(1): 33-48.

Chen B, Yu W W, Liu W H et al., 2012. An assessment on restoration of typical marine ecosystems in China-achievements and lessons. Ocean \& Coastal Management, 57: 53-61.

Conservation International, 2011. Biodiversity Hotspots. Available at: http://sp10.conservation.org/where/priority_areas/hotspots/ Pages/hotspots_main.aspx.

Da Silva V R, Lima J T, Da Silva M J R et al., 2008. Valorisation de résidus d'Eucalyptus utilisés pour la fabrication de coffrets éducatifs. Bois et Forêts des Tropiques, 298(4): 49-51. (in French)

Dewitte O, Jones A, Spaargaren O et al., 2013. Harmonisation of the soil map of Africa at the continental scale. Geoderma, 211: 138-153.

Driscoll C T, Lambert K F, Chapin F S III et al., 2012. Science and society: the role of long-term studies in environmental stewardship. BioScience, 62(4): 354-366. 
Estes L D, Beukes H, Bradley B A et al., 2013. Projected climate impacts to South African maize and wheat production in 2055: a comparison of empirical and mechanistic modeling approaches. Global Change Biology, 19(12): 3762-3774. doi: 10.1111/gcb.12325

Fu B, Li S, Yu X et al., 2010. Chinese ecosystem research network: progress and perspectives. Ecological Complexity, 7(2): 225-233. doi: 10.1016/j.ecocom.2010.02.007

Girard P, Pinta F, Van de Steene L, 2003. Valorisation énergétique des sous-produits de scieries. Bois et Forêts des Tropiques, 277(3): 5-17. (in French)

Gray M, Kalpers J, 2005. Ranger based monitoring in the Virunga-Bwindi region of east-central Africa: a simple data collection tool for park management. Biodiversity and Conservation, 14(11): 2723-2741.

Hartz S M, Pinheiro G C, de Mendonca-Lima A et al., 2012. The potential role of migratory birds in the expansion of araucaria forest. Natureza \& Conservação, 10(1): 52-56.

Henschel J R, Lancaster N, 2013. Gobabeb-50 years of Namib Desert research. Journal of Arid Environments, 93(SI): 1-6. doi: 10.1016/j.jaridenv.2012.09.015

Henschel J, Pauw J, Banyikwa F et al., 2003. Developing the Environmental Long-Term Observatories Network of southern Africa (ELTOSA). South African Journal of Science, 99(3-4): $100-108$.

Heubes J, Schmidt M, Stuch B et al., 2013. The projected impact of climate and land use change on plant diversity: an example from West Africa. Journal of Arid Environments, 96: 48-54.

Hobbie J E, Carpenter S R, Grimm N B et al., 2003. The US Long Term Ecological Research Program. BioScience, 53(1): 21-32. doi: 10.1641/0006-3568(2003)053[0021:TULTER]2.0. $\mathrm{CO} ; 2$

Joubert M, Trollip K, 2011. The SAEON Story. South African Environmental Observation Network, 84. Available at: http://www.saeon.ac.za/The\%20SAEON\%20Story.pdf

Jürgens N, Schmiedel U, Haarmeyer D H et al., 2012. The BIOTA biodiversity observatories in Africa-a standardized framework for large-scale environmental monitoring. Environmental Monitoring and Assessment, 184(2): 655-678.

Kim E S, 2006. Development, potentials, and challenges of the International Long-Term Ecological Research (ILTER) Network. Ecological Research, 21(6): 788-793.

Knapp A K, Smith M D, Hobbie S E et al., 2012. Past, present, and future roles of long-term experiments in the LTER network. BioScience, 62(4): 377-389. doi: 10.1525/bio.2012.62. 4.9

Lane A M J, 1997. The U.K. Environmental Change Network database: an integrated information resource for long-term monitoring and research. Journal of Environmental Management, 51(1): 87-105.

Leciak E, Bah O, 2008. Les végétaux du quotidien: usages des ligneux dans les terroirs de Guinée maritime. Bois et Forêts des Tropiques, 298(4): 77-88. (in French)

Liu X, Zhang L, Hong S, 2011. Global biodiversity research during 1900-2009: a bibliometric analysis. Biodiversity and Con- servation, 20(4): 807-826. doi: 10.1007/s10531-010-9981-z

Luque G M, Bellard C, Bertelsmeier C et al., 2014. The 100th of the world's worst invasive alien species. Biological Invasions, 16(5): 981-985. doi: 10.1007/s10530-013-0561-5

Machange R W, Jenkins A R, Navarro R A, 2005. Eagles as indicators of ecosystem health: is the distribution of Martial Eagle nests in the Karoo, South Africa, influenced by variations in land-use and rangeland quality? Journal of Arid Environments, 63(1): 223-243.

Michener W K, Waide R B, 2009. The evolution of collaboration in ecology: lessons from the United States Long Term Ecological Research Program. In: Olson G M et al. (eds.). Scientific Collaboration on the Internet. Boston: MIT Press, 297-310.

Newman S H, Chmura A, Converse K et al., 2007. Aquatic bird disease and mortality as an indicator of changing ecosystem health. Marine Ecology Progress Series, 352: 299-309. doi: 10.3354/meps07076

Ogden J C, Baldwin J D, Bass O L et al., 2014a. Waterbirds as indicators of ecosystem health in the coastal marine habitats of Southern Florida: 2. Conceptual ecological models. Ecological Indicators, 44(SI): 128-147.

Ogden J C, Baldwin J D, Bass O L et al., 2014b. Waterbirds as indicators of ecosystem health in the coastal marine habitats of southern Florida: 1. Selection and justification for a suite of indicator species. Ecological Indicators, 44(SI): 148-163.

Olson D M, Dinerstein E, Wikramanayake E D et al., 2001. Terrestrial ecoregions of the World: a new map of life on Earth. BioScience, 51(11): 933-938.

Padmanaba M, Corlett R T, 2014. Minimizing risks of invasive alien plant species in tropical production forest management. Forests, 5(8): 1982-1998. doi: 10.3390/f5081982

Rarieya M, Fortun K, 2010. Food security and seasonal climate information: Kenyan challenges. Sustainability Science, 5(1): 99-114. doi: 10.1007/s11625-009-0099-8

Rejmanek M, Richardson D M, 2013. Trees and shrubs as invasive alien species-2013 update of the global database. Diversity and Distributions, 19(8): 1093-1094. doi: 10.1111/ddi.12075

Ren H, Lyu H F, Shen W J et al., 2009. Sonneratia apetala Buch.Ham in the mangrove ecosystems of China: an invasive species or restoration species? Ecological Engineering, 35(8): 1243-1248. doi: 10.1016/j.ecoleng.2009.05.008

Robertson G P, Collins S L, Foster D R et al., 2012. Long-term ecological research in a human-dominated world. BioScience, 62(4): 342-353. doi: 10.1525/bio.2012.62.4.6

Roda J M, 2002. Le point sur la place des bois tropicaux dans le monde. Bois et Forêts des Tropiques, 274(4): 79-80. (in French)

ROSELT/OSS (Sahara and Sahel Observatory), 2004. Conceptual, Organizational and Operational Framework of ROSELT/ OSS. ROSELT/OSS collection, scientific document n1, Montpellier, 76.

Roy H E, Peyton J, Aldridge D C et al., 2014. Horizon scanning for invasive alien species with the potential to threaten biodiversity in Great Britain. Global Change Biology, 20(12): 


\section{9-3871.}

Saidi A, Pauw J, 2010. Regions and the environment: experiences of environmental research networks in southern Africa. South African Geographical Journal, 92(1): 63-79.

Sala O E, Chapin III F S C, Armesto J J et al., 2000. Global biodiversity scenarios for the year 2100. Science, 287(5459): 1770-1774.

Sales C, 2003. Innovation technologique et valorisation des sous-produits des filières bois. Bois et Forêts des Tropiques, 277(3): 35-43. (in French)

Stork H, Astrin J J, 2014. Trends in biodiversity research-a bibliometric assessment. Open Journal of Ecology, 4: 354-370. doi: 10.4236/oje.2014.47033

Taylor J R, Loescher H L, 2013. Automated quality control methods for sensor data: a novel observatory approach. Biogeosciences, 10(7): 4957-4971. doi: 10.5194/bg-10-4957-2013

Tenhinds W, 1984. Towards monitoring of long-term trends in terrestrial ecosystems. Environmental Conservation, 11(1): 11-18.

UNEP (United Nations Environment Programme), 2010. State of biodiversity in Africa. Available at: http://www.unep.org/delc/
Portals/119/ State\%20of\%20biodiversity\%20in\%20Africa.pdf. UNEP-WCMC (United Nations Environment Programme World Conservation Monitoring Centre), 2012. Data Standards for the World Database on Protected Areas. Cambridge, UK: UNEPWCMC.

Vihervaara P, D'Amato D, Forsius M et al., 2013. Using longterm ecosystem service and biodiversity data to study the impacts and adaptation options in response to climate change: insights from the global ILTER sites network. Current Opinion in Environmental Sustainability, 5(1): 53-66. doi: 10.1016/j. cosust.2012.11.002

Wiens J, Sutter R, Anderson M et al., 2009. Selecting and conserving lands for biodiversity: the role of remote sensing. Remote Sensing of Environment, 113(7): 1370-1381. doi: 10. 1016/j.rse.2008.06.020

Wilson E O, 1988. Biodiversity-Editor's Foreword. Washington DC: National Academy Press, 521.

Yin R S, Yin G P, 2010. China's primary programs of terrestrial ecosystem restoration: initiation, implementation, and challenges. Environmental Management, 45(3): 429-441. 